\title{
Investigating the Antecedents of User Acceptance of Clinical Decision Support Systems: a Case from Saudi Arabia
}

Mohammed Suliman Albahly

King Faisal University

Mohammed Elhassan Seliaman ( $\nabla$ mseliaman@gmail.com )

King Faisal University https://orcid.org/0000-0002-9141-2742

\section{Research article}

Keywords: Clinical Decision Support Systems, Hospital Information Systems, Health Informatics, User Acceptance, Structural Equation Modelling

Posted Date: February 26th, 2021

DOI: https://doi.org/10.21203/rs.3.rs-270359/v1

License: (c) (i) This work is licensed under a Creative Commons Attribution 4.0 International License. Read Full License 


\section{Abstract \\ Background}

The purpose of this paper is to develop an integrated research model to identify the technological and nontechnological factors that influence user acceptance of the CDSS. This model is empirically tested using a data sample collected from selected healthcare facilities in Saudi Arabia.

\section{Methods}

The research study uses the quantitative approach to evaluate the currently implemented CDSS as a part of Hospital Information System BESTCare 2.0 in Saudi Ministry of National Guard Health Affairs. A survey questionnaire is conducted at all Ministry of National Guard Health Affairs hospitals for data collection. Then, the survey data is analyzed using Structural Equation Modeling (SEM) and AMOS 21.0. This analysis includes: measurement instrument reliability, discriminant validity, convergent validity, and hypothesis testing. Moreover, a CDSS usage data sample is extracted from the data warehouse to be analyzed as an additional data source.

\section{Results}

The results of the hypotheses testing show that usability, availability, and medical history accessibility are the important factors influencing user acceptance of CDSS.

\section{Conclusions}

This study provides prudence pertaining to healthcare facilities and their higher management to adopt CDSS.

\section{Introduction}

One of the most significant causes of healthcare mistakes is the inability to access patients' medical records due to lack of implementing health electronic systems at healthcare facilities. It is a global issue affecting healthcare quality [1], [2]. Although the adoption of Electronic Medical Records (EMR) and Computerized Physician Order Entry (CPOE) has increased[3], [1], [4], EMR and CPOE are insufficient to prevent a large number of medication errors without a full integration with intelligent module such as (CDSS) [5], [6].

CDSS are information systems used to enhance decision-making process by matching patients' characteristics to a knowledge base and algorithms to generate warnings, alerts, and recommendations [7]. This definition clarifies the power of integrating patients' characteristics from EMR with CDSS. Usually, CDSS capture structured data from EMR through CPOE such as dosage, frequency, duration, and some other information [8]. Therefore, some research studies categorize EMR and CPOE systems as a prerequisite of 
CDSS [5], [6]. Furthermore, some CDSS are capable of analyzing free text written in EMR such as plan of care, admission notes, outpatient clinic notes, and discharge orders [8].

This research uses BESTCare 2.0 HIS and EMR implemented at Ministry of National Guard Health Affairs (MNGHA) in Kingdom of Saudi Arabia as a case study. BESTCare 2.0 is a complete HIS solution, it mainly consists of the following modules: $\mathrm{CPOE}$, registration, scheduling, billing, nursing information system, EMR, pharmacy, laboratory information system, blood bank, medical imaging information system, operating rooms management, infection control, home health care, rehabilitation, Health Information Management, nutrition and food services, and human resources. BESTCare 2.0 is considered as Evidence-Based Patient Care System that utilizes CDSS clinical rules and inference engine in order to increase patient safety and quality control [12]. The CDSS contains set of defined rules for every medication, CDSS checks physician's entry and compare it with the rules based on patient's information in EMR as shown in Fig. 1.

The main issue that healthcare facilities are facing is the adoption and implementation of CPOE and CDSS [1],[9]. Since physician's task during medication prescribing is a very complicated task, the physician must be aware of patient's biomedical status, history, and medication's interactions and contradictions [13], which makes prescribing medications a very risky process. However, the risk could be prevented if the physicians and pharmacists received real-time warnings and alerts [14]. Hence, CDSS can be considered as a tool used to share clinical knowledge among healthcare practitioners to prevent errors and achieve high-quality healthcare [15], [10]. Some research studies show that there is a high rate of prescriptions errors either because of using handwritten prescriptions or through EMR which doesn't provide real-time clinical alerts [16], [17]. High rates of Adverse Drug Events had been recorded in multiple hospitals in the absence of CDSS [18],[19]. Although some healthcare facilities adopted and implemented CDSS, some studies showed that certain forms of CDSS fall and discontinued [20], [21]. The most common reasons of CDSS failures are Lack of integration to business workflow, poor technical support, training issues, and the huge number of prompted alerts "Alert fatigue" [22], [23], [24]. There is a notable lack of published research investigating the acceptance of CDSSs in Saudi Arabia [86]. Therefore, this research study is intended to examine the antecedents of user acceptance of the currently implemented CDSS as a part of Hospital Information System (HIS) BESTCare 2.0 in Saudi Ministry of National Guard Health Affairs.

While CDSS has received extensive attention from the research community, this research study is motivated by several reasons. First, recent reviews in this domain report an evident need for further research to investigate the effective adoption of ICT in healthcare in general and CDSSs' adoption in particular [25] [26] [27][28]. More specifically, clear gaps are reported in research on factors influencing CDSS implementations including organizational factors, human factors, and technological factors[25] [29] [30]. Second, CDSS adoption studies tend to "overlook the social, cultural and contextual factors potentially influencing their implementation" [30]. Therefore, it is very important to replicate and validate studies assessing the CDSS adoption across different social and cultural contexts [31] [32]. Third, research in Saudi Arabia is very limited in this domain in general [34]. In particular, research investigation of end-users' acceptance of eHealth services in Saudi Arabia is scarce [35]. Fourth, most of the reviewed conducted studies followed the qualitative method focusing on subjective measures [25] [30]. Hence, the rigor of quantitate method is needed. This research used the Structural equation modelling (SEM) technique which is classified as a 
second generation data analysis methods. "These methods are widely acknowledged to be state-of-the-art for high quality statistical analysis in survey research" [36]. "SEM allows the researcher to examine reliability and validity of the measurements together with the examination of the hypotheses contained in the proposed theoretical model" [36].

This remainder of this paper is organized as follows: Sect. 2 presents a theoretical background. Section 3 presents the developed research model and hypotheses, Sect. 4 details the followed research Methodology. Analysis and results are presented in Sect. 5. Discussion of the study findings is presented in Sect. 6. Finally, Sect. 7 concludes the study and highlights its limitations.

\section{Theoretical Background}

This section presents an overview of some prior related research on the CDSS adoption and impact. International standards organization defined EMR as "a repository of information regarding the health status of a subject of care, in computer process-able form" [37]. EMR systems are designed as integrated modules that covered all different types of users including physicians, nurses, pharmacists, radiology and laboratory technologists, and the hospital's management [3]. CDSS is defined as "Information systems that combine medical knowledge with data from clinical information systems or EMR to support, and hopefully improve, individual patient care decisions" [38]. EMR facilitates the physician's job by providing access to a comprehensive medical repository [39], and a structured CPOE and forms. The utilization of CPOE's friendly user interface and CDSS alerts and reminders will minimize medication errors and facilitate monitoring [40]. On the other hand, CDSS and EMR could distract physician's attention and minimize the communication with patients since physician will spend more time working on these tools [41].

\subsection{CDSS adoption and acceptance models}

Some studies show that CDSS has a high failure rate that may be more than 50 percent [42]. The main reasons for the failures were mainly usability issues [43]. Therefore, [26] conducted a systematic review of studies that evaluated CDSS implementation at healthcare facilities in order to identify the factors lead to physicians' acceptance of CDSS. All factors gathered from the reviewed papers were categorized and mapped to Human, Organization and Technology (HOT-fit) framework [44]. (HOT-fit) consists of three main domains: Human, Organization and Technology. Every domain contains some dimensions. The review found that the System Use dimension was the highest reported by 22 papers, and 20 papers were linked to System Quality dimension and 18 papers mentioned Information Quality. The most frequently mentioned factors associated with System Users, System Quality, and Information Quality: Ease of system use - flexibility User Interface design and system messages. On the other hand, the less mentioned dimensions were User Satisfaction and Organizational Environmental by three papers for each of them. This systematic review showed that the factors associated with the Technological and Human domain are the most effective on CDSS acceptance.

The "Fit between Individuals, Task and Technology" (FITT) framework assumes that ICT adoption in healthcare environment depends on how it fits between the attributes of users, technology, and organization 
[45]. The research study [46] applied FITT framework on a fully-integrated health electronic services called "HYGEIAnet". HYGEIAnet is a network of Hospital Information systems, Primary Care Information Systems, and Emergency Information Systems implemented in the hospitals and primary care centers of the Greek island "Crete" [47] [48]. This case study aims to find the factors which influence the adoption of IT services throughout ad distributed health environment, and show FITT's applicability to explain implementation's successes and failures. The research team used both quantitative and qualitative methods during the research including extracted data, interviews, documents review, and site observation. The reasons led to increasing the adoption are healthcare practitioners found the system facilitates their job in terms of retrieving patients' data and monitoring them. The integrated hospital information system consists of Clinical Information System, nursing records, Laboratory Information System (LIS), Electronic Health Records (EHR), and Pictures Archieving and Communications Systems (PACS). After case analysis, the overall success of the previously mentioned systems was due to some initiative covering FITT factors from the implementation team. The main initiatives such as on-job training, 24 hours hot-line support, pilot deployments, and managerial support played a significant role to achieve a high success rate.

\subsection{CDSS Impact}

CDSS success can be measured by its impact in minimizing prescription errors. Prescription errors can be defined as "any preventable event that may cause or lead to inappropriate medication or patient harm when the medication is in the control of the health care professional, patient or consumer" [49]. Medication errors have been categorized into four categories as the following: Serious error (Type A), Major error (Type B), Minor error (Type C), and Trivial error (Type D) [50]. An investigation research has been conducted to analyze the handwritten medication errors at 10 Primary Healthcare Centers from public and private sectors in Riyadh [16]. The research team collected the paper medical records for 1182 patients from public primary care centers and 1200 from private primary care centers. This research proved that the rate of errors is high (near to 1/5) which can harm patients. Since this paper is limited to primary care environment, it's expected to have a higher rate of errors at more complicated facilities which provide emergency and critical care services. CDSS can be good solutions to reduce the high rate of medical mistakes even in stressful circumstances [51]. Moreover, most of studies that discussed CDSS net benefits were focusing on physician's practice. Therefore, there is a need for more research to investigate the CDSS benefits in terms of minimizing errors, and increasing efficiency and effectiveness [25].

\section{Research Model And Hypotheses}

A research model has been developed as a result of integrating the FITT framework into the Hot-fit model. This integrated model is used to analyze the factors of CDSS user acceptance. The developed model utilizes the three domains of FITT framework: Technology, Task, and Individual; and it utilizes the influence between different domains factors of CDSS adoption from Hot-fit model. The model consists of eight independent variables, one mediating variable and one dependent variable as depicted in Fig. 2 . The description of these variables is as follows.

System's usability, is defined as the degree to which the system is friendly and accessible [52]. The users feel that the system is easy-to-use and will help them to perform their tasks without extra effort. This attribute 
influences the fit between individual and technology. Research studies show that more than half of medical information systems fail due to usability issues [53].

System's availability, is defined as the correct technical functioning of the system [54]. The system should be available and accessible anytime and anywhere within the organization. Otherwise, the tasks will not be performed in the required time. This attribute influences the fit between individual and technology, and between task and technology.

Medical history accessibility, is defined as the coverage of the extent to which complete, accurate, organized, understandable, up-to-date, and timely information is provided in the system for the health practitioners to obtain information about any of their intended objectives [55]. Since it is very important to utilize the medical history of the patient to support decision making process and to avoid any order duplication, the medical history should be accessible and clearly stated in the system. This attribute influences the fit between individual and technology, and between task and technology.

Therefore, three hypotheses related to technology are identified as follows:

H1. System's usability has a positive influence on intention to use.

H2. System's availability has a positive influence on intention to use.

H3. Medical history accessibility has a positive influence on intention to use.

Task impact, is defined as the users' perceptions about the extent to which the system allows them to complete their tasks effectively and to improve their work [56]. The users feel that the system allows them to accomplish more work than would otherwise be possible. This attribute influences the fit between individual and task.

Task-Technology Fit, is defined as the degree to which the system assists users in performing their work or coursework [57]. The user finds that the system's functions are fit for the requirements of tasks or coursework. This attribute influences the fit between task and technology.

Thus, two hypotheses related to task are identified as follows:

H4. Task impact has a positive influence on intention to use.

H5. Task-Technology Fit has a positive influence on intention to use.

Training sessions construct, is defined as the extent to which an individual has been trained about the system through courses, training, manuals, and so on [52]. This attribute influences the fit between individual and technology. The lack of training is reported as an obstacle to using CDSS for supporting healthcare decisions [58] [59].

User support, is defined as the perception of how the system's provider delivers the service to the user [52]. The user will be more satisfied when the provider solved the system's issues rapidly. This attribute influences 
the fit between individual and technology.

Override Justification, is defined as the reason for rejecting system's alerts [60]. This attribute influences the fit between individual and technology. Findings from IS research suggest that physicians will accept systems that allow them to have professional autonomy and practice individual judgment [61].

Intention to use, is defined as the user intends to use the system [62]. The user is willing to let the system assist her/him in deciding which medication to prescribe.

Net benefit, is defined as the benefits of the system as perceived by the user [63]. The system has reduced the time and effort it takes to support decision making.

Therefore, four hypotheses related to individual are identified as follows:

H6. Override justification has a positive influence on intention to use.

H7. Training sessions have a positive influence on intention to use.

H8. User support has a positive influence on intention to use.

H9. Intention to use has a positive influence on Net benefit.

\section{Research Methodology}

The research methodology followed in this research is a quantitative approach to achieve the research goals. A survey questionnaire is developed as the main measurement instrument to collect the health practitioners' responses measuring their behaviors towards the implemented CDSS. The survey questionnaire is used because it has many advantages in the IS research. These advantages include the ease of reuse, comparing different perspectives, capability of predicting behaviors and capability of testing types of theoretical propositions objectively [36]. The survey questionnaire provides a clear picture of health practitioners' experience with such systems. In addition, this study presents the CDSS alerts popped up to health practitioners during the medication prescribing process in EMR, and their actions and behaviors towards these alerts. The medication prescribing process requires the physician's order and pharmacist's verification or change. The research team used Oracle Data warehouse for extraction and Tableau for Visualization. The study implementation went through the following phases: understanding the business workflow, identification of the scope of the required data, data extraction, data modeling, and identification of dimensions and measures, and dashboards design.

\subsection{Survey Design and Instruments Development}

The survey design process started by reviewing the related literature to find suitable survey questionnaire items for each model construct. After identifying the questionnaire items, the survey was designed and sent to six domain experts (University professors of Computer Science and Information Systems) in order to test its face and content validity. The experts thankfully provided the researchers with some notes to enhance the 
survey questionnaire. In addition, the process of survey evaluation continued with survey pilot study administered to some users chosen randomly to evaluate the questions in terms of clarity, precision, and time taken to complete the survey. Moreover, the data used in this study is collected from five hospitals that belong to Ministry of National Guard. The hospitals are located in Riyadh, Jeddah, Ahsa, Dammam, and Madinah. The researchers assume that the questions are suitable for all hospitals as the system is standardized and follows the regulations and legislation of the ministry. The users received the same training materials and support process. After that, the survey was written in English language, published online and a notification sent to around 350 users through the department's managers. The scope of this survey includes physicians and pharmacists from all experience levels. Appendix 1 shows the latent construct items. Five points Likert scale [64] with anchors of strongly disagree to strongly agree was used to measure each item. The other part of this research which is Datawarehouse (DW) data extraction was conducted at King Abdulaziz Hospital - Al Ahsa, Saudi Arabia between January 1, 2018, and December 31, 2018. Physicians and pharmacists from all medical departments and within different experience levels were included in this study.

\subsection{Sample Demographic Characteristics}

Table 1 shows the demographics of the respondents: Gender, age group, job title, and hospital. Male respondents are (85\%) which reflects the Saudi culture in workplace that involves male more than female. It was expected to get most of the respondents from Riyadh (56.7\%) since King Abdulaziz Medical City in Riyadh is the largest healthcare facility among National Guard facilities. Jeddah, Madinah, and Dammam respondents were the least. Majority of collected responses are from the Central and Eastern regions. 
Table 1

Descriptive statistics

\begin{tabular}{|lll|}
\hline Measure & Item & Percent \\
\hline \multirow{3}{*}{ Age } & Male & $85 \%$ \\
\cline { 2 - 3 } & Female & $15 \%$ \\
\cline { 2 - 3 } & 30 years or less & $25 \%$ \\
\cline { 2 - 3 } & Between 31 and 40 & $38.3 \%$ \\
\cline { 2 - 3 } Job title & Between 41 and 50 & $30 \%$ \\
\cline { 2 - 3 } & More than 50 years & $6.7 \%$ \\
\cline { 2 - 3 } & Consultant & $18.3 \%$ \\
\cline { 2 - 3 } & Resident & $11.7 \%$ \\
\cline { 2 - 3 } & Clinical pharmacist & $20 \%$ \\
\cline { 2 - 3 } Hospital & Pharmacist & $50 \%$ \\
\cline { 2 - 3 } & Riyadh & $56.7 \%$ \\
\cline { 2 - 3 } & Jeddah & $1.7 \%$ \\
\cline { 2 - 3 } & Ahsa & $31.7 \%$ \\
\cline { 2 - 3 } & Dammam & $3.2 \%$ \\
\cline { 2 - 3 } & Madinah & $6.7 \%$ \\
\cline { 2 - 3 } & \\
\cline { 2 - 3 } & & \\
& &
\end{tabular}

\section{Analysis And Results}

This research used Analysis of a Moment Structure (AMOS 21.) software to analyze the research model. AMOS is used to assess the psychometric properties of measurement model and estimate the parameters of the structural model. AMOS enables the simultaneous analysis indicator variables, allowing extensive interactions examination among latent and moderating predictor variable indicators [65].

\subsection{The Measurement Model}

Reliability results are shown in Table 2 . The results indicate that the measures are robust in terms of internal consistency reliability as indexed by the composite reliability [66]. The composite reliabilities of the measures range from 0.72 to 0.98 , exceeding the recommended threshold value of 0.70 . In addition, Cronbach's alpha (CA) has been calculated to assess constructs reliability. The acceptable score of CA is > 0.7 . However, 0.6 is acceptable if the constructs passed the validity tests [67]. Cronbach's alpha is significant for all constructs and ranged from 0.78 to 0.95 except Override justification scoring Cronbach's alpha of 0.6. 
Table 2

Reliability results

\begin{tabular}{|llll|}
\hline Construct & No of items & Cronbach's alpha & Composite reliability \\
\hline System's usability & 2 & 0.78 & 0.87 \\
\hline System's availability & 2 & 0.85 & 0.88 \\
\hline Medical history & 3 & 0.86 & 0.95 \\
\hline Training sessions & 2 & 0.90 & 0.92 \\
\hline User support & 3 & 0.79 & 0.93 \\
\hline Override justification & 2 & 0.60 & 0.73 \\
\hline Task impact & 2 & 0.84 & 0.92 \\
\hline Task-Technology Fit & 3 & 0.95 & 0.98 \\
\hline Intention to use & 3 & 0.92 & 0.94 \\
\hline Net Benefit & 3 & 0.93 & 0.97 \\
\hline
\end{tabular}

Construct validity is "the extent to which a measure assesses the construct that it is intended or supposed to measure" [68]. Confirmatory Factor Analysis (CFA) is used in this study to assess validity. The assessment includes convergent validity and discriminant validity. Convergent validity can be achieved if each construct's $\mathrm{AVE}$ is $>=0.5$ and the composite reliability is $>=0.7$. Discriminant validity can be achieved if the square root of AVE of each construct is higher than the inter-construct correlations with all other constructs[68].

Table 3 presents convergent validity assessment by calculating Composite reliability and AVE. AVE for all the variables exceeded 0.50 . 
Table 3

Convergent validity

\begin{tabular}{|lll|}
\hline Variable constructs & Composite reliability & AVE \\
\hline System's usability & 0.87 & 0.65 \\
\hline System's availability & 0.88 & 0.76 \\
\hline Medical history & 0.95 & 0.66 \\
\hline Training sessions & 0.92 & 0.82 \\
\hline User support & 0.93 & 0.56 \\
\hline Override justification & 0.73 & 0.50 \\
\hline Task impact & 0.92 & 0.73 \\
\hline Task-Technology Fit & 0.98 & 0.87 \\
\hline Intention to use & 0.94 & 0.74 \\
\hline Net benefit & 0.97 & 0.84 \\
\hline
\end{tabular}

Table 4 presents discriminant validity assessment results by calculating the square root of AVE for each construct and comparing it with constructs correlations. The square root of AVE must be higher than all constructs correlations with other constructs [68]. The Table shows that all constructs passed the test.

Table 4

Discriminant validity

\begin{tabular}{|lllllllllll|}
\hline & TT & IU & SU & NB & MH & TS & US & OJ & TI & SA \\
\hline TT & 0.931 & & & & & & & & & \\
\hline IU & 0.650 & 0.860 & & & & & & & & \\
\hline SU & 0.790 & 0.669 & 0.806 & & & & & & & \\
\hline NB & 0.682 & 0.767 & 0.806 & 0.916 & & & & & & \\
\hline MH & 0.744 & 0.753 & 0.720 & 0.777 & 0.812 & & & & & \\
\hline TS & 0.652 & 0.364 & 0.671 & 0.476 & 0.652 & 0.906 & & & & \\
\hline US & 0.655 & 0.449 & 0.518 & 0.533 & 0.500 & 0.716 & 0.748 & & & \\
\hline OJ & 0.454 & 0.217 & 0.452 & 0.302 & 0.204 & 0.315 & 0.228 & 0.707 & & \\
\hline TI & 0.850 & 0.630 & 0.651 & 0.772 & 0.723 & 0.616 & 0.530 & 0.341 & 0.854 & \\
\hline SA & 0.720 & 0.601 & 0.800 & 0.676 & 0.740 & 0.657 & 0.435 & 0.313 & 0.727 & 0.872 \\
\hline
\end{tabular}

TT: Task-Technology fit. IU: Intention to Use. SU: Systems Usability. NB: Net Benefit. MH: Medical History. TS: Training Sessions. US: User Support. OJ: Override Justification. TI: Task Impact. SA: System Availability. 
Factor loadings for each variable have to be at least 0.5 or the variable becomes a candidate for deletion [69]. The factor loadings have been calculated using AMOS for each construct. Table 5 shows the results from a lower threshold of 0.544 to upper threshold of 0.958 . The results show that the factor loading for each item is highly significant $(p<0.001)$. 
Table 5

Factor loadings

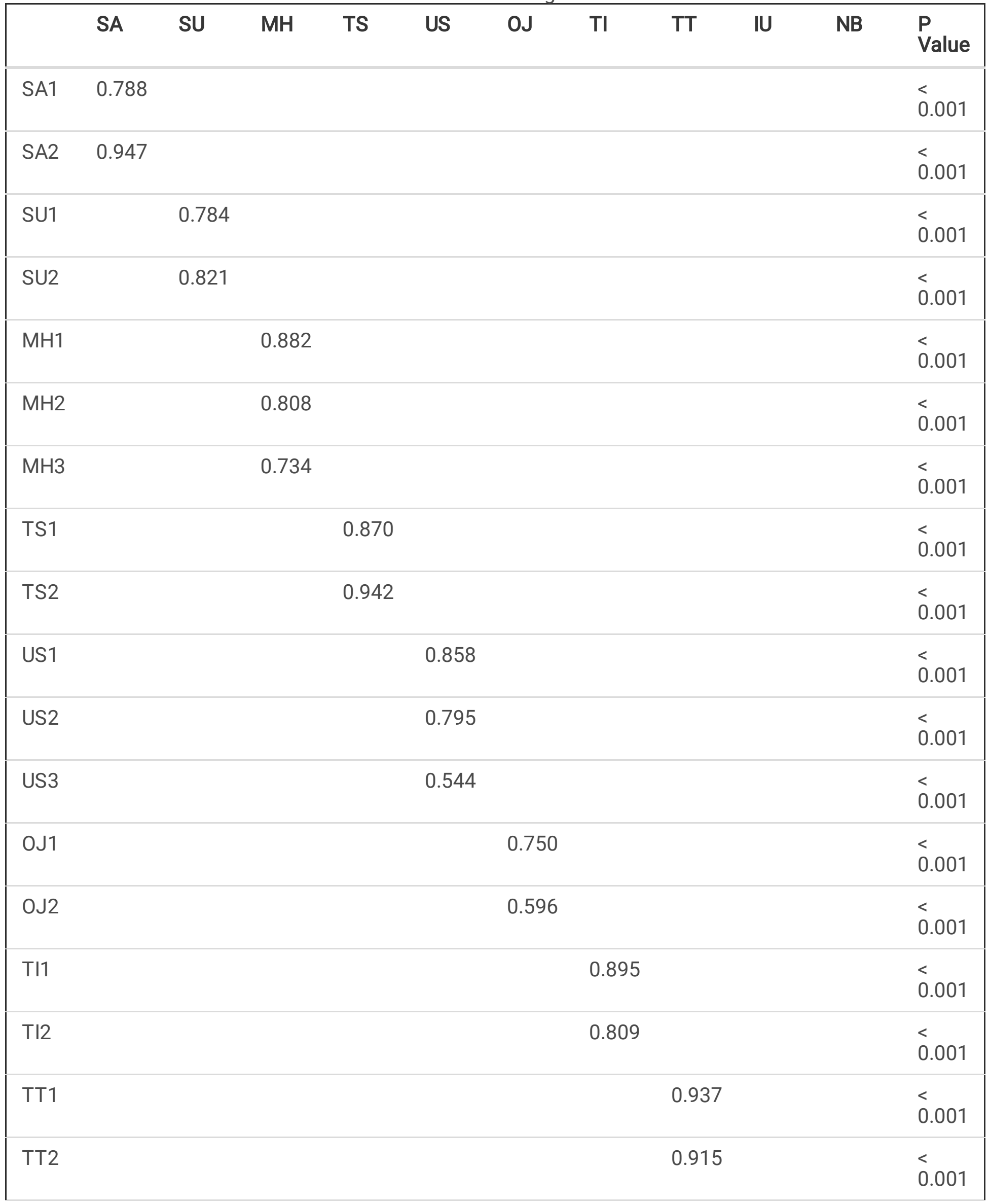




\begin{tabular}{|c|c|c|c|c|c|c|c|c|c|c|}
\hline SA & SU & $\mathrm{MH}$ & TS & US & OJ & $\mathrm{TI}$ & $\mathrm{TT}$ & IU & NB & $\begin{array}{l}P \\
\text { Value }\end{array}$ \\
\hline TT3 & & & & & & & 0.941 & & & $\begin{array}{l}< \\
0.001\end{array}$ \\
\hline IU1 & & & & & & & & 0.911 & & $\begin{array}{l}<.001 \\
0.00\end{array}$ \\
\hline IU2 & & & & & & & & 0.904 & & $\begin{array}{l}< \\
0.001\end{array}$ \\
\hline IU3 & & & & & & & & 0.867 & & $\dot{0}_{0.001}$ \\
\hline NB1 & & & & & & & & & 0.883 & $\begin{array}{l}< \\
0.001\end{array}$ \\
\hline NB2 & & & & & & & & & 0.904 & $\begin{array}{l}< \\
0.001\end{array}$ \\
\hline NB3 & & & & & & & & & 0.958 & $\begin{array}{l}< \\
0.001\end{array}$ \\
\hline
\end{tabular}

TT: Task-Technology fit. IU: Intention to Use. SU: Systems Usability. NB: Net Benefit. MH: Medical History. TS: Training Sessions. US: User Support. OJ: Override Justification. TI: Task Impact. SA: System Availability.

\subsection{The structural model}

Structural model is a technique used to analyze the relationships between latent constructs and measured variables. Figure 3 shows the structural model results. All beta path coefficients are positive and statistically significant (at $\mathrm{p}<0.001)$.

In the structural model, the value $\mathrm{R}^{2}$ is the square of the correlation between the predicted values and the observed values and it indicates the percentage of variation explained by the regression line out of the total variation. Compared to prior models of CDSS acceptance, the model reported better explanatory power of variance in behavior intention to use CDSS. While the model in [70] explained $28 \%$ of variance and the model in [79] explained $47 \%$ of variance, the explanatory power of the model developed in this study is $75 \%$ of variance in behavior intention. Moreover, the model explained $84 \%$ of the variance in perceived net benefits. The value $\beta$ is the correlation coefficient between two variables. Table 6 presents hypothesis testing results. 
Table 6

Hypothesis conclusion

Hypothesis

Finding

Conclusion

H1. System's usability has a positive influence on intention to use.

Yes: $(\beta=0.35, \mathrm{P}<$

Supported

$0.001)$

H2. System's availability has a positive influence on intention to use.

Yes: $(\beta=0.34, P<$

Supported

$0.001)$

H3. Medical history accessibility has a positive influence on intention to use.

Yes: $(\beta=0.45, P<$ $0.001)$

Supported

H4. Task impact has a positive influence on intention to use.

Yes: $(\beta=0.32, P<$

Supported

$0.001)$

H5. Task-Technology Fit has a positive influence on intention to use.

Yes: $(\beta=0.39, P<$

Supported

$0.001)$

H6. Override justification has a positive influence on intention to use.

Yes: $(\beta=0.13, P<$

Supported

H7. Training sessions has a positive influence on intention to use.

Yes: $(\beta=0.16, P<$

Supported

$0.001)$

H8. User support has a positive influence on intention to use.

Yes: $(\beta=0.23, P<$ $0.001)$

Supported

H9. Intention to use has a positive influence on Net benefit.

Yes: $(\beta=0.57, P<$

Supported $0.001)$

\section{Hypothesis 1}

stated that system's usability has a positive influence on intention to use. A positive path coefficient ( $\beta=$ $0.35, P<0.001)$ supports hypothesis 1 . System's availability was hypothesized to have a positive effect on intention to use. As predicted, it was supported $(\beta=0.34, P<0.001)$. Hypothesis 3 stated that medical history accessibility has a positive influence on intention to use. A positive path coefficient $(\beta=0.45, P<0.001)$ supports hypothesis 3 . Task impact was hypothesized to have a positive effect on intention to use. A positive path coefficient $(\beta=0.32, P<0.001)$ revealed that hypothesis 4 was strongly supported. Hypothesis 5 stated that Task-Technology Fit has a positive influence on intention to use. As proposed, the hypothesis was supported $(\beta=0.39, P<0.001)$. Hypothesis 6 stated that Override justification has a positive influence on intention to use. A positive path coefficient $(\beta=0.13, P<0.001)$ supports hypothesis 6 . Training sessions was hypothesized to have a positive effect on intention to use. A positive path coefficient $(\beta=0.16, P<$ 0.001) revealed that hypothesis 7 was strongly supported. Hypothesis 8 stated that user support has a positive influence on intention to use. A positive path coefficient $(\beta=0.23, P<0.001)$ supports hypothesis 8 . Finally, hypothesis 9 stated that intention to use has a positive influence on net benefit. A positive path coefficient $(\beta=0.57, P<0.001)$ supported hypothesis 9 .

\subsection{CDSS Usage Data analysis}


In addition to the survey questionnaire data, a sample of 46212 medication alerts is extracted from the actual system usage history. The most occurred alerts are related to (Single Dose Maximum) and (Drug \& Drug Severity Major) as shown in Table 7.

Table 7

Total of alerts by type

\begin{tabular}{|lll|}
\hline Alert & Total & Percentage \\
\hline Class/Group & 1005 & $2.17 \%$ \\
\hline Contraindicated & 2622 & $5.67 \%$ \\
\hline Cross-Reaction & 2145 & $4.64 \%$ \\
\hline Drug-Drug Severity Major & 18447 & $39.92 \%$ \\
\hline Drug-Drug Severity Moderate & 9 & $0.02 \%$ \\
\hline Ingredient & 72 & $0.16 \%$ \\
\hline Not recommended & 1 & $0.001 \%$ \\
\hline Professional Intervention Required & 3210 & $6.95 \%$ \\
\hline Professional Review Suggested & 13 & $0.03 \%$ \\
\hline Single Dose Maximum & 18688 & $40.44 \%$ \\
\hline Grand Total & 46212 & $100 \%$ \\
\hline
\end{tabular}

In order to explore the physician's behavior during different cases and situations, a new important attribute which is visit type was added to this descriptive study. Table 8 shows the total and percentage of alerts and physician's override by visit type. As shown in the Table 8, the physicians show high acceptance rate for the received alerts. In the most critical area at any hospital which is ER, physicians accepted $(78.14 \%)$ of the alerts and overrode (21.86\%). Similar results occurred at inpatient and outpatient since (74.18\%) and $(71.17 \%)$ of the alerts were accepted by physicians respectively. These override rates are very low when compared to high alert overrides rates ranging between $49 \%$ and $96 \%$ as reported in recent research studies [70], [71].

Table 8

Alerts and override by visit type

\begin{tabular}{|lllllll|}
\hline & \multicolumn{3}{l}{ Total } & \multicolumn{3}{c|}{ Percentage } \\
\hline Physician's override? & ER & Inpatient & Outpatient & ER & Inpatient & Outpatient \\
\hline No & 6234 & 17575 & 10350 & $78.14 \%$ & $74.18 \%$ & $71.17 \%$ \\
\hline Yes & 1744 & 6116 & 4193 & $21.86 \%$ & $25.82 \%$ & $28.83 \%$ \\
\hline
\end{tabular}

\section{Findings And Discussion}


This study examines how certain variables affect healthcare practitioners' intention to use CDSS and how these factors affect their performance and clinical decisions. The researchers developed a model based on the integration between FITT and Hot-fit models by incorporating some additional variables.

The technology variables: usability, availability, and medical history accessibility were found to be important factors to accept using CDSS.

First, we asserted that usability has a positive influence on intention to use CDSS. Extensive use of questionnaires to examine CDSS usability and user satisfaction is crucial for integrating user feedback into the CDSS development process [72]. The results support this hypothesis. This finding is consistent with observations made by previous research investigating acceptance of CDSS in other countries [73]. However, the result is conflicting with the findings of [33] where no significant effect of effort expectancy on intention when considering user experience as a moderating variable when investigating Saudi users acceptance of IT. This might be because the users interaction with CDSS is different than their interaction with other information systems.

Second, we hypothesized that system's availability has a positive influence on intention to use CDSS. The results indicate that system's availability has significant impact on user acceptance of CDSS. Prior research has shown that system availability has a positive significant impact on the perceived quality of health care systems [74]. In turns, perceived quality is a significant predictor of CDSS acceptance.

Third, as expected, the results show that Medical history accessibility and information quality has a positive influence on intention to use CDSS. This finding is consistent with some prior research [75], [76], [77]. However, some previous research findings report no significant effect of information quality on HIS acceptance as mediated by perceived usefulness and perceived ease of use [78].

The second domain of the developed model includes individual (human) variables. This domain included the override justification, user training and technical support variables. This study results show that override justification has a positive influence on intention to use CDSS. Although a number of previous studies has examined factors influencing acceptance of CDSS alerts [60], our study is the first study that examines the association between override justification and alert acceptance. Physicians thinks that they should be allowed to override the CDSS recommendations and provide their supporting evidence [79]. Without having the option to override CDSS alerts, physicians may consider CDSS as real threat to their professional autonomy [79]. Results from previous studies show that if the physicians consider CDSS as a real threat to their professional autonomy and individual judgment then their acceptance of CDSS will be impacted negatively [31]. Actual usage data extracted from the BESTCare 2.0 data warehouse shows that physicians accepted $(78.14 \%)$ of the alerts and overrode $(21.86 \%)$ in the ER. Similar results occurred at inpatient and outpatient since $(74.18 \%)$ and $(71.17 \%)$ of the alerts were accepted by physicians respectively.

User training is considered as the first contact between the healthcare practitioner and the system. A qualified instructor who has a knowledge of system's functionalities, a clearly designed material and documents, and learning management system were the main objectives of MNGHA to be accomplished through the training process. We asserted that training sessions has a positive influence on intention to use 
CDSS. The results support this hypothesis. This finding is consistent with other studies[80]. In [81], [82], the research team found that training has a positive impact on intention to use the system. Therefore, it is essential to consider the amount of training needed before the CDSS implementation [80]. Moreover, [83] conducted a qualitative study that suggested certain organization characteristics, such as training, are influencing use of CDSS. As a result, (56\%) of survey questionnaire respondents accepted the training approach followed by MNGHA, and (21\%) didn't like it, and the rest were neutral.

Another important factor is the technical support provided by Information Systems and Informatics Department (ISID) to the end-users after system's implementation. The results show that user support has a positive influence on intention to use CDSS. Based on survey results, more than (45\%) of the respondents consider ISID employees able to solve the technical problems and are helping them with courtesy. However, $(18 \%)$ of the respondents disagree.

The third domain of the developed model covers task variables which measure the impact of system adoption on healthcare practitioners' daily tasks and productivity. The results support the assertion that task impact has a positive significant effect on physicians' intention to use CDSS. This finding is in line with results in prior research in general [31], [84], [85]. In particular, this result validates the finding of the qualitative analysis in [86]. This result can be interpreted by the fact that $(70.5 \%)$ of the respondents declared that the system helped them to meet patient's needs, and (74\%) of them stated that the system allows them to accomplish more work than before. Also actual usage data extracted from the DW shows that consultants faced 5796 alerts out of 160725 orders (3.60\%) which are classified as the best performance among all job titles. Staff physicians prescribed 466158 medication orders and received 25138 alerts (5.40\%). Finally, residents who have 5 years or less of experience prescribed 205455 orders and there were 15233 alerts $(7.41 \%)$ generated to them. Results from prior research indicate that system usability as measured by effort expectancy has less significant effect than task impact as measured by performance expectancy on use intention [31], [73]. However, our results show that CDSS usability $(\beta=0.35, P<0.001)$ has more significant than task impact $(\beta=0.32, P<0.001)$. This is might be because most of the respondents are willing to use the system to help them through decision-making process and assist them to choose the most suitable medication for each case. Moreover, a significant impact of the system on healthcare practitioner's performance and patient outcomes has been proven since the results show that the system reduced the time and effort taken by healthcare practitioners to accomplish their work and make clinical decisions.

Concerning perceived net benefits of CDSS, most of studies that discussed CDSS net benefits were focusing on physician's practice. There is a very limited research that discussed net benefits in terms of increasing CDSS efficiency and effectiveness [25]. Results from the current study show that there is a significant positive correlation between CDSS acceptance and the net benefits $(\beta=0.57, P<0.001)$. Thus, when CDSS users realize the net benefits of CDSS and believe that the system has changed their job significantly, then they be more likely to accept the system.

A successful design and implementation of the CDSS requires careful consideration of these three mentioned domains in order to shorten treatment process and minimize the time health practitioner spent to 
perform the daily tasks. This is one of the critical factors required by the clinical environment which leads to increase the acceptance rate.

\section{Conclusion}

This study found predictive factors influencing healthcare practitioners' intention to use BESTCare 2.0 to provide healthcare services and assist them in decision making based on the developed model. As expected, the study found that the ten used variables are critical and predictive factors in CDSS acceptance. The results confirmed that the variables played an important role in the outcomes of CDSS acceptance. Results from hypotheses testing show that system's usability, system's availability, medical history accessibility, task impact and task-technology-fit positively correlate with user intention to use.

This study provides prudence pertaining to healthcare facilities and their higher management to adopt CDSS. The study proved the positive impact of CDSS implementation on healthcare quality and saving financial expenses. Another important contribution to the literature and Saudi healthcare facilities is the development of a new acceptance model with specific factors and variables. Such a model will facilitate the measurement of users' acceptance and behavior towards medical systems which will shorten the required time to choose a new medical system for any organization and provides the factors of success and lessons learned.

This research has some limitations. First, the study used a cross-sectional survey questionnaire to collect the data sample making it difficult to investigate causal relationships [31] among the research model constructs. Future research might use a longitudinal survey questionnaire to collect the data over a longer period of time in order get more reliable interpretations.

Second, our study only used the quantitative method. Mixing quantitative and qualitative methods might be a good future research direction to validate the results of this study.

Third, subjects of this study are from five hospitals but not all hospitals are equally represented in sample. That might lead to some bias in the data set. Although, the five hospitals are underneath one administration and are sharing the same policies, regulations, standards, salary scales benefits, facilities, and working hours, future research studies should consider uniform representation of all the five hospital in the data set to avoid any chance for bias.

\section{Declarations}

\section{Authors Contributions}

MSB is responsible to review literature from previous researches in the fields of medical informatics and decision support systems. Moreover, he is responsible for data collection, data analysis, and discussions section. MES and MSB are responsible to design the acceptance model and define survey items. In addition, both researchers approved the final version. All authors have read and approved the manuscript.

\section{Acknowledgment}

Page 19/31 
The authors of this research would like to acknowledge the support provided by College of Computer Sciences and Information Technology and the Deanship of Postgraduate Studies at King Faisal University and Saudi Ministry of National Guard Health Affairs. The authors wish to confirm that there are no known conflicts of interest associated with this publication and there has been no significant support for this work that could have influenced its outcome.

\section{Ethics approval and consent to participate}

This study has been approved by the research ethics committee at King Faisal University: HAPO-05-HS-003, REC REF NUMBER KFU-REC/2021-01-16. This approval covers the signed consent for participation.

\section{Consent for publication}

This manuscript does not contain any individual person's data in any form

\section{Availability of data and materials}

Not applicable.

\section{Competing interests}

"The authors declare that they have no competing interests"

\section{Funding}

There is no fund for this research currently.

\section{Authors' contributions}

The two authors contributed to this research. Conceptualization, MS and ME; methodology, MS and ME; software, MS; data analysis, MS; writing-original draft preparation, MS; writing-review and editing ME.

All authors have read and approved the manuscript.

\section{A conflict of interest statement}

On behalf of all authors, the corresponding author states that there is no conflict of interest.

\section{References}

[1] R. E.-Y. and L. Klieb, "Electronic medical records adoption and use: Understanding the barriers and the levels of adoption for physicians in the USA," in 2014 IEEE 16th International Conference on e-Health Networking, Applications and Services (Healthcom), 2014, pp. 506-512.

[2] P. C. T. et Al, "Personal Health Records: Definitions, Benefits, and Strategies for Overcoming Barriers to Adoption," J. Am. Med. Informatics Assoc., vol. 13, no. 2, pp. 121-126, 2006. 
[3] P. Hayrinen, K., Saranto, K., \& Nykanen, "Definition, structure, content, use and impacts of electronic health records: A review of the research literature," Int. J. Med. Inform., no. 77, pp. 291-304, 2008.

[4] M. M. Altuwaijri, "Achieving excellence in Electronic Health Record deployment in Middle East hospitals," in 2011 4th International Conference on Biomedical Engineering and Informatics (BMEI), 2011, pp. 19191923.

[5] J. A. Lyman, W. F. Cohn, M. Bloomrosen, and D. E. Detmer, "Clinical decision support: Progress and opportunities," J. Am. Med. Informatics Assoc., vol. 17, no. 5, pp. 487-492, 2010.

[6] H. J. Nebeker JR, Hoffman JM, Weir CR, Bennett CL, "High rates of adverse drug events in a highly computerized hospital," Arch. Intern. Med., vol. 165, no. 10, pp. 1111-1116, 2005.

[7] A. X. G. et Al, "Effects of Computerized Clinical Decision Support Systems on Practitioner Performance and Patient Outcomes: A Systematic Review," Jama, vol. 293, no. 10, pp. 1223-1238, 2005.

[8] S. Jensen, P. B., Jensen, L. J., \& Brunak, “Mining electronic health records: Towards better research applications and clinical care," Nat. Rev., vol. 13, no. 6, pp. 395-405, 2012.

[9] S. N. and R. M. D. N. R. Rahim, "Review on barriers and considerations of Clinical Decision Support System for medication prescribing," in 2015 IEEE Student Conference on Research and Development (SCOReD), 2015, pp. 489-494.

[10] C. W. van Rosse, F., Maat, B., Rademaker, C. M., van Vught, A. J., Egberts, A. C., \& Bollen, "The effect of computerized physician order entry on medication prescription errors and clinical outcome in pediatric and intensive care: a systematic review," Pediatrics, vol. 123, no. 4, pp. 1184-1190, 2009.

[11] “HIMSS Stage 7." [Online]. Available: http://www.himssanalyticsasia.org/emram/stage7hospitals.asp.

[12] “BESTCare 2.0.” [Online]. Available: http://www.skhic.com.sa/bestcare-2.0/.

[13] A. D. N. J. Arney, R.L. Street Jr., "Factors Shaping Physicians' Willingness to Accommodate Medication Requests," Eval. Health Prof., pp. 1-17, 2012.

[14] M. W. M. J. et Al, "Effects of clinical decision-support systems on practitioner performance and patient outcomes: a synthesis of high-quality systematic review findings," J. Am. Med. Informatics Assoc., vol. 18, no. 3, pp. 327-334, 2011.

[15] B. D. D. and L. H. Liang Xiao, G. Cousins, T. Fahey, "Developing a rule-driven clinical decision support system with an extensive and adaptative architecture." e-Health Networking, Applications and Services (Healthcom)," in 2012 IEEE 14th International Conference, 2012, pp. 250-254.

[16] S. C. and I. C. Z. Alsulami, "Medication errors in the Middle East countries: A systematic review of the literature," Eur. J. Clin. Pharmacol., vol. 69, no. 4, pp. 995-1008, 2013. 
[17] T. Khoja, T., Neyaz, Y., Qureshi, N. A., Magzoub, M. A., Haycox, A., \& Walley, “Medication errors in primary care in riyadh city, saudi arabia," East. Mediterr. Heal. J., vol. 17, no. 2, p. 156, 2011.

[18] D. Hug, Balthasar \& Witkowski, Daniel \& Sox, Colin \& Keohane, Carol \& Seger, Diane \& Yoon, Catherine \& Matheny, Michael \& Bates, "Adverse drug event rates in six community hospitals and the potential impact of computerized physician order entry for prevention," J. Gen. Intern. Med., vol. 25, no. 1, pp. 31-38, 2010.

[19] A. Z. et Al., "Features of electronic Early Warning systems which impact clinical decision making," in 2012 25th IEEE International Symposium on Computer-Based Medical Systems (CBMS), 2012, pp. 1-4.

[20] Y. Shah, NR \& Seger, AC \& Seger, Diane \& Fiskio, JM \& Kuperman, GJ \& Blumenfeld, B \& Recklet, EG \& Bates, David \& Gandhi, "Improving acceptance of computerized prescribing alerts in ambulatory care," J. Am. Med. Informatics Assoc., vol. 13, no. 1, pp. 5-11, 2006.

[21] P. R. Weingart SN, Toth M, Sands DZ, Aronson MD, Davis RB, “Physicians' decisions to override computerized drug alerts in primary care," Arch. Intern. Med., vol. 163, no. 21, pp. 2625-2631, 2003.

[22] P. S. Moxey A, Robertson J, Newby D, Hains I, Williamson M, "Computerized clinical decision support for prescribing: provision does not guarantee uptake," J. Am. Med. Informatics Assoc., vol. 17, no. 1, pp. 25-33, 2010.

[23] M. B. Wright A, Sittig DF, Ash JS, Sharma S, Pang JE, "Clinical decision support capabilities of commercially-available clinical information systems," J. Am. Med. Informatics Assoc., vol. 16, no. 5, pp. 637-644, 2009.

[24] S. A. Kesselheim AS, Cresswell K, Phansalkar S, Bates DW, "Clinical decision support systems could be modified to reduce 'alert fatigue' while still minimizing the risk of litigation," Health Aff., vol. 30, no. 12, pp. 2310-2317, 2011.

[25] L. W. P. and M. W. M. J. E. Kilsdonk, "Factors influencing implementation success of guideline-based clinical decision support systems: A systematic review and gaps analysis," Int. J. Med. Inform., vol. 98, pp. 56-64, 2017.

[26] E. K. et Al, "Factors known to influence acceptance of clinical decision support systems," Stud. Health Technol. Inform., pp. 150-154, 2011.

[27] F. Reis, W. C., Bonetti, A. F., Bottacin, W. E., Reis Jr, A. S., Souza, T. T., Pontarolo, R., ... \& Fernandez-Llimos, "Impact on process results of clinical decision support systems (CDSSs) applied to medication use: overview of systematic reviews.," Pharm. Pract., 2017.

[28] R. Shawahna, "Merits, features, and desiderata to be considered when developing electronic health records with embedded clinical decision support systems in Palestinian hospitals: a consensus study.," BMC Med. Inform. Decis. Mak., p. 216, 2019. 
[29] W. Schuh, C., de Bruin, J. S., \& Seeling, "Clinical decision support systems at the Vienna General Hospital using Arden Syntax: Design, implementation, and integration.," Artif. Intell. Med., pp. 24-33, 2018.

[30] A. Moja, L., Liberati, E. G., Galuppo, L., Gorli, M., Maraldi, M., Nanni, O., ... \& Vaona, “Barriers and facilitators to the uptake of computerized clinical decision support systems in specialty hospitals: protocol for a qualitative cross-sectional study.," Implement. Sci., p. 105, 2014.

[31] H. Esmaeilzadeh, P., Sambasivan, M., Kumar, N., \& Nezakati, "Adoption of clinical decision support systems in a developing country: Antecedents and outcomes of physician's threat to perceived professional autonomy.," Int. J. Med. Inform., vol. 84, no. 8, pp. 548-560, 2015.

[32] R. Liberati, E. G., Ruggiero, F., Galuppo, L., Gorli, M., González-Lorenzo, M., Maraldi, M., ... \& Vespignani, "What hinders the uptake of computerized decision support systems in hospitals? A qualitative study and framework for implementation.," Implement. Sci., vol. 12, no. 1, p. 113, 2017.

[33] J. Al-Gahtani, S. S., Hubona, G. S., \& Wang, "Information technology (IT) in Saudi Arabia: Culture and the acceptance and use of IT.," Inf. Manag., vol. 44, no. 8, pp. 681-691, 2007.

[34] K. Alshahrani, A., Stewart, D., \& MacLure, "A systematic review of the adoption and acceptance of eHealth in Saudi Arabia: Views of multiple stakeholders.," Int. J. Med. informatics., 2019.

[35] and K. M. Alshahrani, Abdullah, Derek C. Stewart, "Factors influencing health managers' acceptance of eHealth services in Saudi Arabia.," Comput. Methods Programs Biomed., 2019.

[36] J. Recker, "Scientific research in information systems: a beginner's guide.," Springer Sci. Bus. Media., 2012.

[37] "International Standards Organization," Health informatics -Electronic health record - Definition, scope, and context, 2005. [Online]. Available: http://www.iso.org/iso/catalogue_detail.htm?csnumber=39525.

[38] E. Greenes, Robert A., Clinical decision support: the road ahead. Elsevier, 2011.

[39] and M. D. D. Garets, "Electronic medical records vs. electronic health records: yes there is a difference," in HIMSS Analytics, 2006.

[40] and B. N. S. Felt-Lisk, L. Johnson, C. Fleming, R. Shapiro, "Toward understanding EHR use in small physician practices," Health Care Financ. Rev., vol. 31, no. 1, pp. 11-32, 2009.

[41] A. A. Khudair, "Electronic health records: Saudi physicians' perspective," in 5th IET Seminar on Appropriate Healthcare Technologies for Developing Countries, 2008, pp. 1-7.

[42] A. Trivedi, Madhukar \& Kern, Janet \& Marcee, A \& Grannemann, B \& Kleiber, Beverly \& Smith, Tawny \& Altshuler, Kenneth \& McClelland, "Development and implementation of computerized clinical guidelines: barriers and solutions," Methods Inf. Med., vol. 41, no. 5, pp. 435-442, 2002. 
[43] M. Varonen, Helena \& Kortteisto, Tiina \& Kaila, "What may help or hinder the implementation of computerized decision support systems (CDSSs): a focus group study with physicians," Fam. Pract., vol. 25, no. 3, pp. 162-167, 2008.

[44] L. Yusof, Maryati \& Kuljis, Jasna \& Papazafeiropoulou, Anastasia \& Stergioulas, "An evaluation framework for Health Information Systems: human, organization and technology-fit factors (HOT-fit)," Int. J. Med. Inform., vol. 77, no. 6, pp. 386-398, 2008.

[45] C. M. E. Ammenwerth, C. Iller, "IT-adoption and the interaction of task, technology and individuals: a fit framework and a case study," BMC Med. Inform. Decis. Mak., vol. 6, no. 1, p. 3, 2006.

[46] M. T. and A. Kouroubali, "Organizational factors affecting successful adoption of innovative eHealth services: A case study employing the FITT framework," Int. J. Med. Inform., vol. 78, no. 1, pp. 39-52, 2009.

[47] S. C. O. E. Leisch, M. Tsiknakis, "An architectural framework for the integration of geographically distributed heterogeneous autonomous medical information systems," in Proceedings of the EuroPACS'96 conference, 1996, pp. 73-77.

[48] S. C. O. M. Tsiknakis, D. Katehakis, "An open, component-based information infrastructure for integrated health information networks," Int. J. Med. Inform., vol. 68, no. 1-3, pp. 3-26, 2002.

[49] "The standard. Rockville," United States pharmacopoeia. 1995.

[50] N. R. et Al, "A classification of prescription errors," J. R. Coll. Gen. Pract., vol. 39, pp. 110-112, 1989.

[51] S. Phillips-Wren, G., Jefferson, T., \& McKniff, "Cognitive bias and decision aid use under stressful conditions," J. Decis. Syst., vol. 28, no. 2, pp. 162-184, 2019.

[52] W. Hung, "Factors Influencing the Success of National Healthcare Services Information Systems: An Empirical Study in Taiwan," J. Glob. Inf. Manag. An Off. Publ. Inf. Resour. Manag. Assoc., vol. 20, no. 3, 2012.

[53] T. Carroll, C., Marsden, P., Soden, P., Naylor, E., New, J., \& Dornan, "Involving users in the design and usability evaluation of a clinical decision support system.," Comput. Methods Programs Biomed., vol. 69, no. 2, pp. 123-135, 2002.

[54] E. Marimon, Frederic \& Vidgen, Richard \& Barnes, Stuart \& Cristobal, "Purchasing behaviour in an online supermarket: The applicability of ES-QUAL," Int. J. Mark. Res., vol. 52, no. 1, pp. 111-129, 2010.

[55] Y. Shareef, Mahmud \& Kumar, Vinod \& Kumar, Uma \& Dwivedi, "e-Government Adoption Model (GAM): Differing service maturity levels," Gov. Inf. Q., vol. 28, no. 1, pp. 17-35, 2011.

[56] S. S. \& R. S. \& D. J. B. \& V. Sambamurthy, "The effects of social network structure on enterprise systems success: A longitudinal multilevel analysis," Inf. Syst. Res., vol. 23, no. 3-part-1, pp. 658-678, 2012.

[57] H. L. and Y. Yang, "Toward an understanding of the behavioral intention to use a social networking site: An extension of task-technology fit to social-technology fit," Comput. Human Behav., vol. 34, pp. 323-332, 
[58] T. Grace, A., Mahony, C., O’Donoghue, J., Heffernan, T., Molony, D., \& Carroll, “Evaluating the effectiveness of clinical decision support systems: the case of multimorbidity care," J. Decis. Syst., vol. 22, no. 2, pp. 97108, 2013.

[59] W. Razmak, J., Bélanger, C. H., \& Farhan, "Managing patients' data with clinical decision support systems: a factual assessment," J. Decis. Syst., vol. 27, no. 3, pp. 123-145, 2018.

[60] R. Zenziper, Yael \& Kurnik, Daniel \& Matok, Ilan \& Halkin, Hillel \& Markovits, Noa \& Ziv, Amitai \& Shamiss, Ari \& Loebstein, “Prescriber response to computerized drug alerts for electronic prescriptions among hospitalized patients," Int. J. Med. Inform., vol. 107, pp. 70-75, 2017.

[61] Y. Alohali, M., Carton, F., \& O'Connor, "Investigating the antecedents of perceived threats and user resistance to health information technology: a case study of a public hospital," J. Decis. Syst., vol. 29, no. 1, pp. 27-52, 2020.

[62] C. E.-D.-C. \& D. W. S. Anthony Vance, "Examining trust in information technology artifacts: the effects of system quality and culture," J. Manag. Inf. Syst., vol. 24, no. 4, pp. 73-100, 2008.

[63] H. Wixom, Barb \& Watson, "An empirical investigation of the factors affecting data warehousing success," MIS Q., pp. 17-41, 2001.

[64] H. M. Blalock, "Estimating measurement error using multiple indicators and several points in time.," $A m$. Sociol. Rev., vol. 35, no. 1, pp. 101-110, 1970.

[65] IBM, “IBM AMOS.” [Online]. Available: https://www.ibm.com/us-en/marketplace/structural-equationmodeling-sem.

[66] N. S. Raju, "The reliability of a criterion-referenced composite with the parts of the composite having different cutting scores.," Educ. Psychol. Meas., vol. 42, no. 1, pp. 113-129, 1982.

[67] J. R. A. Santos, “Cronbach's alpha: A tool for assessing the reliability of scales.," J. Ext., vol. 37, no. 2, pp. $1-5,1999$.

[68] B. Bringhurst, David \& Watson, Curtis \& Miller, Scott \& Duncan, "The reliability and validity of the Outcome Rating Scale: A replication study of a brief clinical measure," J. Br. Ther., vol. 5, no. 14, 2006.

[69] R. Hair, Joseph F. "Black, WC, Babin, BJ, \& Anderson, Multivariate data analysis, 7th ed. 2010.

[70] M. M. Olakotan, O. O., \& Yusof, "Evaluating the alert appropriateness of clinical decision support systems in supporting clinical workflow," J. Biomed. Inform., 2020.

[71] M. M. Olakotan, O. O., \& Yusof, "Evaluating the appropriateness of clinical decision support alerts: A case study," J. Eval. Clin. Pract., 2020. 
[72] N. Souza-Pereira, L., Pombo, N., Ouhbi, S., Felizardo, V., \& Garcia, “Clinical Decision Support Systems for Chronic Diseases: A Systematic Literature Review," Comput. Methods Programs Biomed., 2020.

[73] Y. C. Chang, I. C., Hwang, H. G., Hung, W. F., \& Li, “Physicians' acceptance of pharmacokinetics-based clinical decision support systems," Expert Syst. Appl., vol. 33, no. 2, pp. 296-303, 2007.

[74] L. Ayaad, O., Alloubani, A., ALhajaa, E. A., Farhan, M., Abuseif, S., Al Hroub, A., \& Akhu-Zaheya, "The role of electronic medical records in improving the quality of health care services: Comparative study," Int. J. Med. Inform., vol. 127, pp. 63-67, 2019.

[75] C. R.-F. Hsiao J-L, Wu W-C, "Factors of accepting pain management decision support systems by nurse anesthetists.," BMC Med. Inform. Decis. Mak., vol. 13, no. 16, 2013.

[76] C. R. Lu CH, Hsiao JL, "Factors determining nurse acceptance of Hospital Information System," Comput. informatics, Nurs., vol. 30, no. 5, pp. 257-264, 2012.

[77] K. A. Alipour J, Mehdipour Y, "Factors Affecting Acceptance of Hospital Information Systems in Public Hospitals of Zahedan University of Medical Sciences: A Cross-Sectional Study," J. Med. Life, vol. 12, no. 4, pp. 403-410, 2019.

[78] H. J.-L. Chen R-F, "An investigation on physicians' acceptance of hospital information systems: A case study," Int. J. Med. Inform., vol. 81, no. 12, pp. 810-820, 2012.

[79] D. C. Trinkley, K. E., Blakeslee, W. W., Matlock, D. D., Kao, D. P., Van Matre, A. G., Harrison, R., ... \& Malone, "Clinician preferences for computerised clinical decision support for medications in primary care: a focus group study," BMJ Heal. care informatics, vol. 26, no. 1, 2019.

[80] L. Mahadevaiah, G., RV, P., Bermejo, I., Jaffray, D., Dekker, A., \& Wee, "Artificial intelligence-based clinical decision support in modern medical physics: Selection, acceptance, commissioning, and quality assurance.," vol. 47, no. 5, p. Medical Physics, 2020.

[81] D. B. et Al, "Evaluating Acceptance and User Experience of a Guideline-based Clinical Decision Support System Execution Platform," J. Med. Syst., vol. 37, no. 2, pp. 1-9, 2013.

[82] O. A. Moghbeli F, Langarizadeh M, Kouhestani A, "Modeling the Acceptance of Hospital Information Systems among Nurses An Extended Technology Acceptance Model," Iran. J. Med. Informatics, vol. 7, no. 1, 2018.

[83] D. D. Randell R, "Organisational influences on nurses' use of clinical decision support systems," Int. J. Med. Inform., vol. 79, no. 6, pp. 412-421, 2010.

[84] H. Sambasivan, M., Esmaeilzadeh, P., Kumar, N., \& Nezakati, "Intention to adopt clinical decision support systems in a developing country: effect of physician's perceived professional autonomy, involvement and belief: a cross-sectional study," BMC Med. Inform. Decis. Mak., vol. 12, no. 1, 2012. 
[85] O. Kissi, J., Dai, B., Dogbe, C. S., Banahene, J., \& Ernest, “Predictive factors of physicians' satisfaction with telemedicine services acceptance.," Health Informatics J., vol. 26, no. 3, 2020.

[86] D. Aljarboa, S., Miah, S. J., \& Kerr, "Perceptions of the adoption of Clinical Decision Support Systems in the Saudi Healthcare Sector," in 24th Asia-Pacific Decision Science Institute International Conference (APDSI), 2019.

\section{Appendix}

Appendix A 


\section{Constructs and items}

\section{System's usability}

SU1. This system is easily used [52].

SU2. This system has a quick response [52].

\section{System's availability}

SA1. This system is always available for business [54].

SA2. This system launches and runs right away [54].

\section{Medical history accessibility}

MH1. Information provided in the system is up-to-date [55].

MH2. Information provided in patient's profile is easy to understand [55].

MH3. The system provides all patient relevant information necessary to fulfill my needs [55].

\section{Training sessions}

TS1. I consider the training used for this system is adequate [52].

TS2. I completely accept the training approach of this system [52].

\section{User support}

US1. The provider (ISID) is very sophisticated with this system [52].

US2. The provider (ISID) of this system is able to rapidly solve the operating problems [52].

US3. Generally, the provider (ISID) of this system treats its customers with courtesy [52].

\section{Override justification}

OJ1. If I override a drug alert, it is because the risk of the drug (or drug combination) is acceptable after considering the therapeutic benefit [60].

OJ2. If I override a drug alert, it is because this drug alert is not clinically important for the given patient [60].

\section{Task impact}

TI1. The system helps me to meet patient's needs [56].

TI2. The system allows me to accomplish more work than would otherwise be possible [56].

\section{Task-Technology Fit}

TT1. In my opinion, the system's functions are suitable for helping me complete my task [57].

TT2. In my opinion, the system's functions are enough to help me complete my task [57].

TT3. In my opinion, the system's functions are fit for the requirements of my work or coursework [57]. 
IU1. I am willing to use the system as an aid to help with my decisions about which medication to prescribe [62].

IU2. I am willing to let the system assist me in deciding which medication to prescribe [62].

IU3. I am willing to use the system as a tool that suggests to me a number of medications from which I can choose [62].

\section{Net benefit}

NB1. The system has changed my job significantly [63].

NB2. The system has reduced the time it takes to support decision making [63].

NB3. The system has reduced the effort it takes to support decision making [63]s.

\section{Figures}

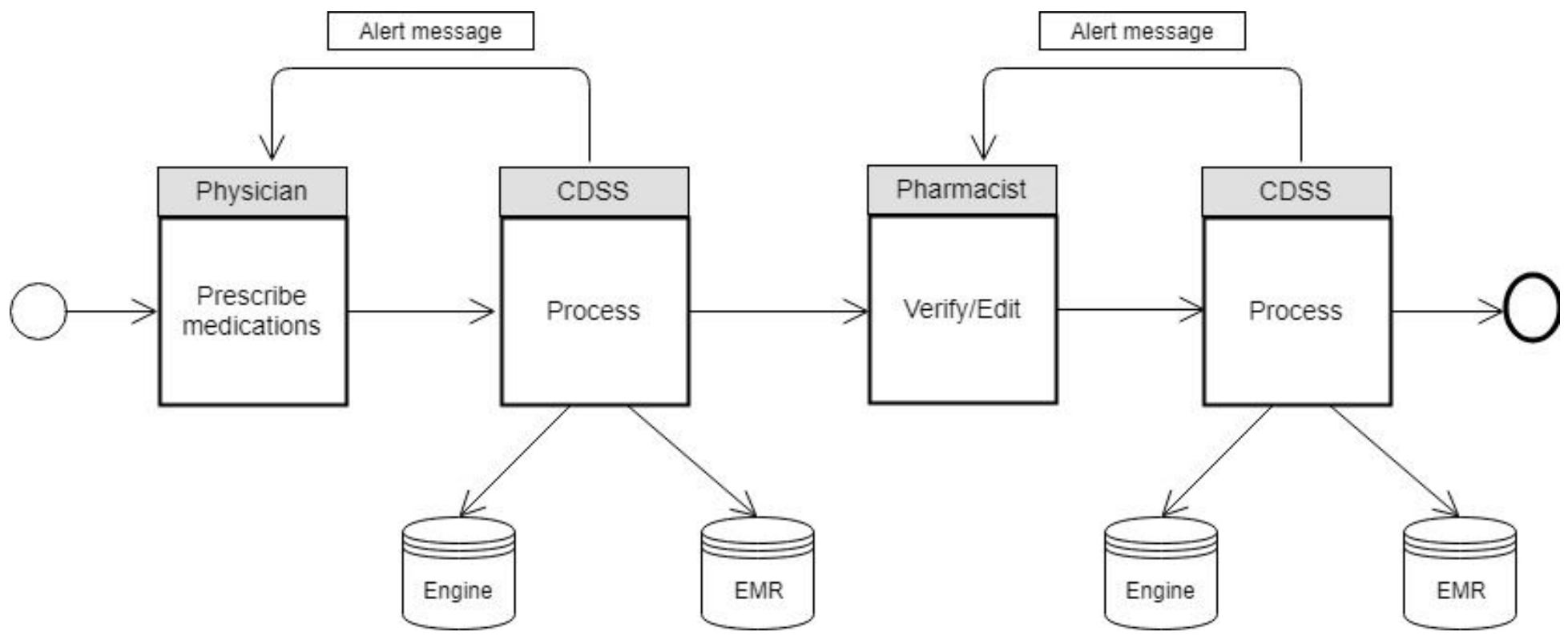

Figure 1

CDSS workflow in BESTCare 2.0 


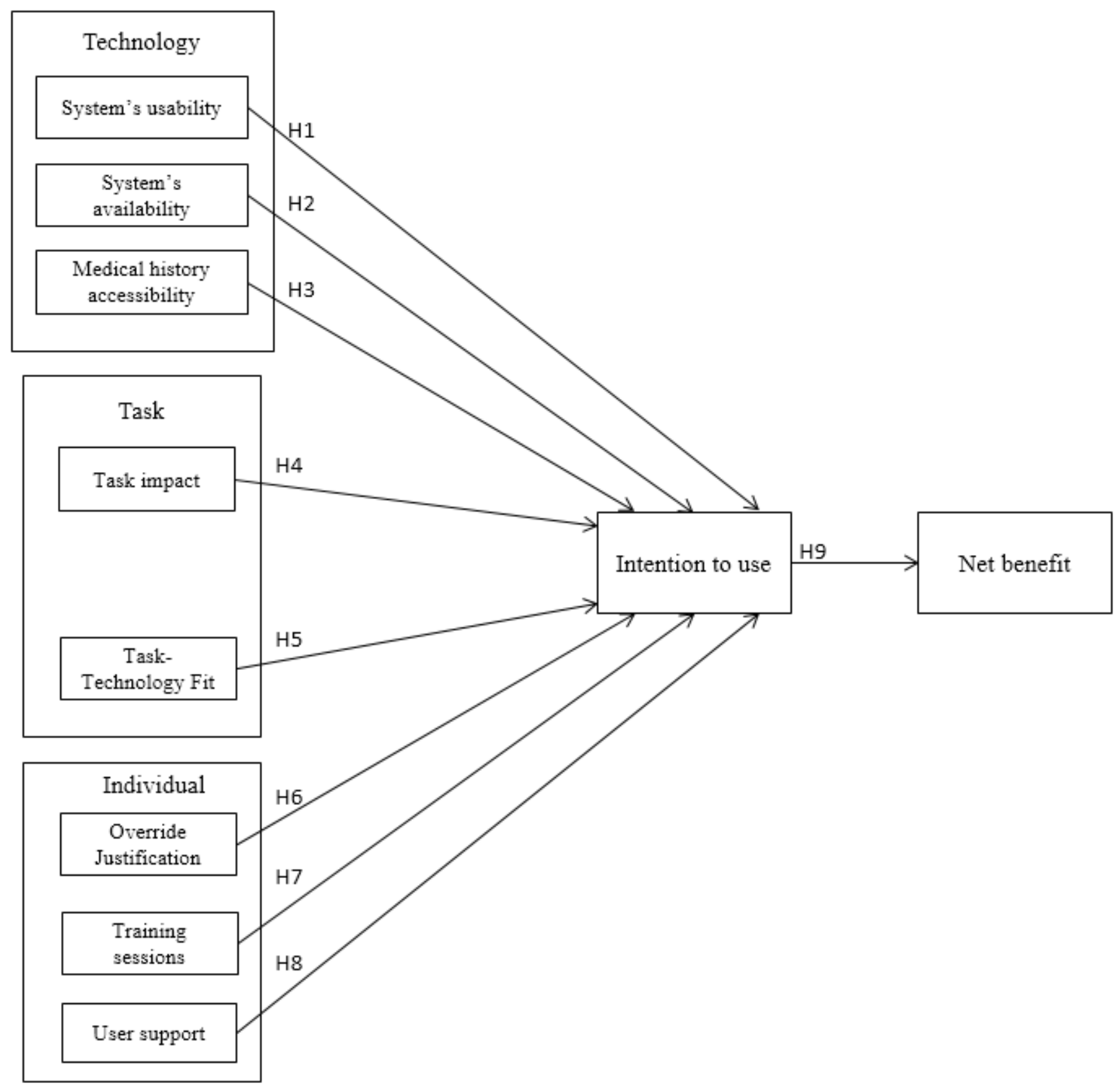

Figure 2

The research model with the hypotheses 


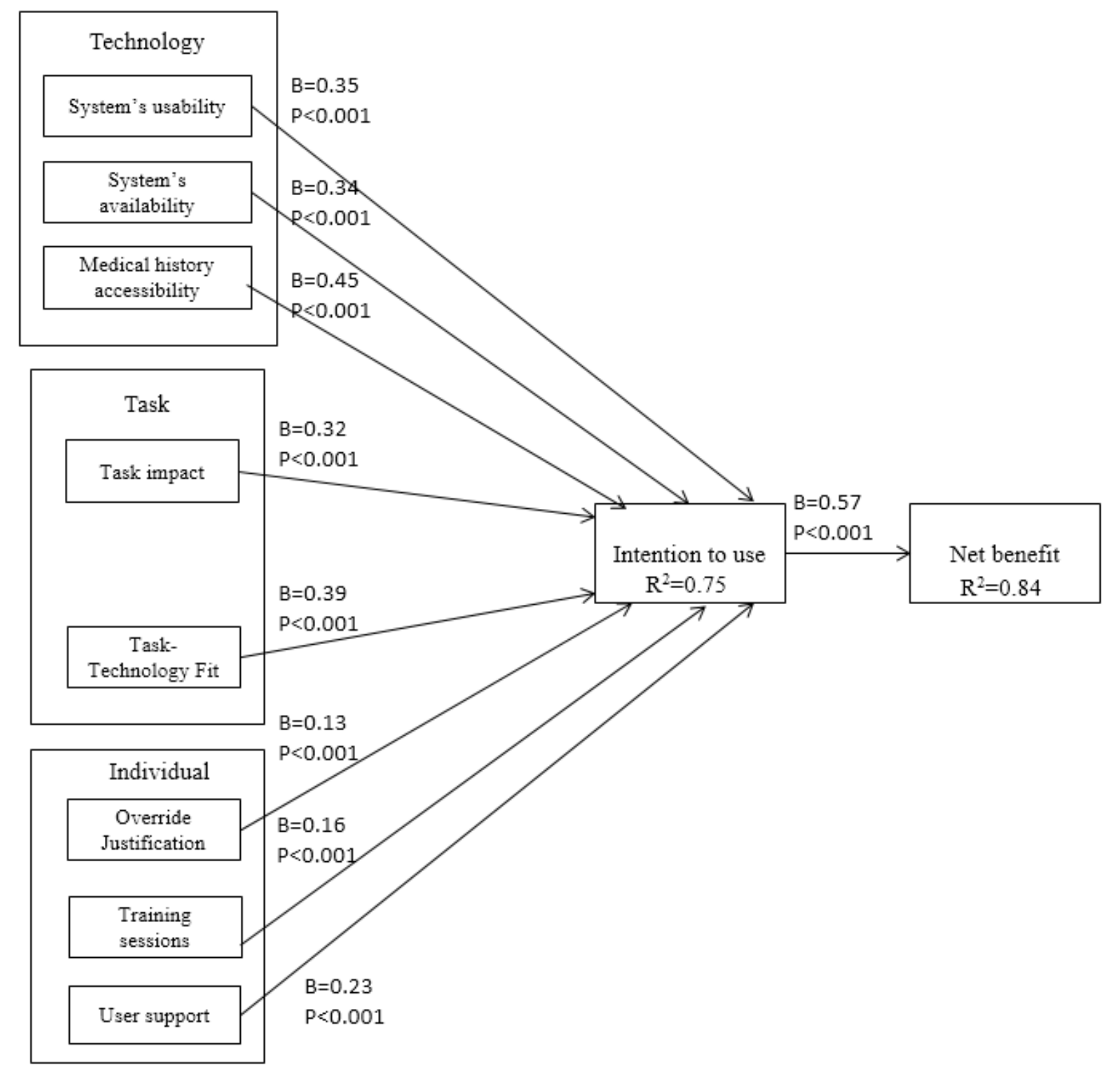

Figure 3

The structural model 